03.4

\title{
Экспериментальное исследование коэффициента гидродинамического сопротивления охлажденной твердой сферы при малых числах Рейнольдса
}

\author{
(C) В.А. Архипов, С.А. Басалаев, К.Г. Перфильева, С.Н. Поленчук, А.С. Усанина
}

Национальный исследовательский Томский государственный университет, Томск, Россия

E-mail: leva@niipmm.tsu.ru

Поступило в Редакцию 21 октября 2020 г.

В окончательной редакции 28 декабря 2020 г.

Принято к публикации 29 декабря 2020 г.

\begin{abstract}
Представлены результаты экспериментального исследования гравитационного осаждения охлажденной твердой сферической частицы в вязкой жидкости в диапазоне чисел Рейнольдса $\mathrm{Re}=0.01-1.32$. Показано значительное снижение скорости стационарного осаждения (до 30\%) охлажденной частицы. Получены эмпирические зависимости для скорости осаждения и коэффициента гидродинамического сопротивления частицы в диапазоне разности температур жидкости (глицерин, силиконовое масло) и частицы $\Delta T=0-210 \mathrm{~K}$.
\end{abstract}

Ключевые слова: твердая сферическая частица, гравитационное осаждение, охлажденная частица, скорость осаждения, коэффициент гидродинамического сопротивления.

DOI: 10.21883/PJTF.2021.07.50800.18592

Движение в несущей среде частиц дисперсной фазы (твердые частицы, капли, пузырьки) представляет интерес при решении ряда практических задач экологии, угольной промышленности, химической технологии, теплоэнергетики и др. Закономерности движения отдельной частицы дисперсной фазы в первую очередь определяются силой сопротивления [1]:

$$
F_{D}=C_{D} S_{m} \frac{\rho_{l}\left(u_{p}-u_{l}\right)^{2}}{2}
$$

где $C_{D}$ - коэффициент сопротивления, $S_{m}-$ площадь миделева сечения частицы, $\rho_{l}-$ плотность несущей среды, $u_{p}, u_{l}$ - скорости частицы и несущей среды.

Корректное определение коэффициента сопротивления играет ключевую роль при создании адекватных моделей многофазных течений. Большинство опубликованных зависимостей для $C_{D}$ получено в изотермических условиях (температуры среды $T_{l}$ и частицы $T_{p}$ одинаковы). В ряде технологических процессов $T_{p}$ может быть намного выше или ниже $T_{l}$ (плазмохимический синтез керамических порошков, процессы охлаждения частиц в аппаратах химической технологии и т.д.). Нагретая (или охлажденная) поверхность частицы влияет на теплофизические характеристики среды (в первую очередь на коэффициент динамической вязкости) в пограничном слое вблизи частицы и в конечном счете на скорость частицы и коэффициент сопротивления. В большинстве публикаций представлены результаты математического и физического моделирования движения нагретых частиц в газообразной среде [2-9]. Экспериментальному исследованию движения нагретых частиц в жидкости посвящены единичные публикации [10]. Как показано в [3], наибольшее влияние разности температур $\Delta T=T_{p}-T_{l}$ на коэффициент сопротивления реализуется в области малых чисел Рейнольдса $\operatorname{Re} \sim 1$.

B настоящей работе представлены результаты экспериментального исследования скорости осаждения одиночной охлажденной твердой сферы в неизотермических условиях в вязкой жидкости в диапазоне чисел Рейнольдca $\operatorname{Re}=0.01-1.32$.

Исследование проводилось на установке, состоящей из вертикально установленной прозрачной кюветы с жидкостью и системы визуализации процесса осаждения частицы. Кювета, выполненная в виде прямоугольной призмы размером $300 \times 300 \times 900 \mathrm{~mm}$ (объемом 81 1), изготовлена из оптического стекла толщиной $15 \mathrm{~mm}$. Видеосъемка высокоскоростной видеокамерой „Citius C100“ проводилась с пространственным разрешением $576 \times 1024$ пикселей, темпом $300 \mathrm{fps}$ и временем экспозиции 0.5-2.0 ms. Для контроля расстояния, пройденного частицами, использовалась масштабная линейка с ценой деления $1 \mathrm{~mm}$, отградуированная с учетом оптического искажения стенками кюветы.

В качестве жидкости использовались глицерин и полиметилсилоксановая жидкость марки ПМС-10000. Плотность используемых жидкостей $\rho_{l}$ при комнатной температуре $T_{l}=293 \mathrm{~K}$ измерялась ареометром. Коэффициент динамической вязкости жидкостей $\mu_{l}$ при температуре $T_{l}=293 \mathrm{~K}$ определялся по измеренной скорости стационарного осаждения твердой сферической частицы в стоксовском режиме $(\operatorname{Re}<0.01)$

$$
\mu_{l}=\frac{g D_{p}^{2}\left(\rho_{p}-\rho_{l}\right)}{18 u_{p}},
$$

где $g$ - ускорение свободного падения.

Значения $\rho_{l}, \mu_{l}$ для глицерина и ПМС-10000 при $T_{l}=293 \mathrm{~K}$ приведены в таблице. В экспериментах ис- 
Характеристики жидкостей при $T_{l}=293 \mathrm{~K}$

\begin{tabular}{c|c|c}
\hline Жидкость & $\rho_{l}, \mathrm{~kg} / \mathrm{m}^{3}$ & \multicolumn{1}{c}{$\mu_{l}, \mathrm{~Pa} \cdot \mathrm{s}$} \\
\hline Глицерин & $1260 \pm 5$ & $1.38 \pm 0.02$ \\
ПМС-10000 & $974 \pm 5$ & $11.17 \pm 0.02$
\end{tabular}

пользовались шарики из стали марки 95X18 диаметром $D_{p}=6.75,8.73$ и $15.10 \mathrm{~mm}$. Плотность материала частиц $\rho_{p}=7753 \mathrm{~kg} / \mathrm{m}^{3}$ рассчитывалась по измеренным значениям диаметра $D_{p}$ и массы набора из $N=20-100$ шариков.

В экспериментах твердые сферические частицы охлаждались до температуры $T=250 \mathrm{~K}$ в холодильной установке и до температуры $T=83 \mathrm{~K}$ в жидком азоте. Температура охлажденной частицы измерялась с помощью цифрового мультиметра марки АРPA-109N. Время, необходимое для полного охлаждения частицы до заданной температуры (время выравнивания температуры в объеме частицы), рассчитывалось по формуле [11]:

$$
t_{1}=\frac{D_{p}^{2}}{8 \chi_{p}}
$$

где $\chi_{p}-$ коэффициент температуропроводности материала частиц.

Сравнительные эксперименты проводились в изотермических условиях $\left(T_{p}=T_{l}=293 \mathrm{~K}\right)$. В процессе осаждения охлажденной частицы в жидкости возможен ее конвективный нагрев. Оценка характерного времени нагрева частицы проводилась по формуле [12]:

$$
t_{2}=\frac{1}{3} \frac{D_{p}^{2}}{\chi_{p}} \frac{\lambda_{p}}{\lambda_{l}}
$$

где $\lambda_{l}, \lambda_{p}$ - коэффициенты теплопроводности жидкости и материала частиц.

Оценка времени нагрева поверхности частицы $t_{2}$ по формуле (2) показала, что $t_{2}$ намного больше времени осаждения частиц в кювете $t$ (в частности, для глицерина $t=2.24-4.5 \mathrm{~s}, t_{2}=204-342 \mathrm{~s}$; для ПМС-1000 $\left.t=6.05-31.9 \mathrm{~s}, t_{2}=357.6-1788 \mathrm{~s}\right)$.

На рис. 1 приведены зависимости пройденного частицей расстояния $s$ от времени $t$, полученные при покадровой обработке видеосъемки процесса осаждения в силиконовой жидкости ПМС-10000. Из приведенных графиков следуют линейность зависимости $s(t)$ и, следовательно, квазистационарность процесса осаждения.

Результаты видеосъемки процесса гравитационного осаждения частиц в изотермических и неизотермических условиях показали, что для охлажденных частиц скорость осаждения меньше, чем в случае $T_{p}=T_{l}$. С увеличением разности температур $\Delta T=T_{l}-T_{p}$ разность скоростей увеличивается. При минимальной температуре частицы $T_{p}=83 \mathrm{~K}$ снижение скорости осаждения частицы в глицерине составляет $~ 30 \%$.

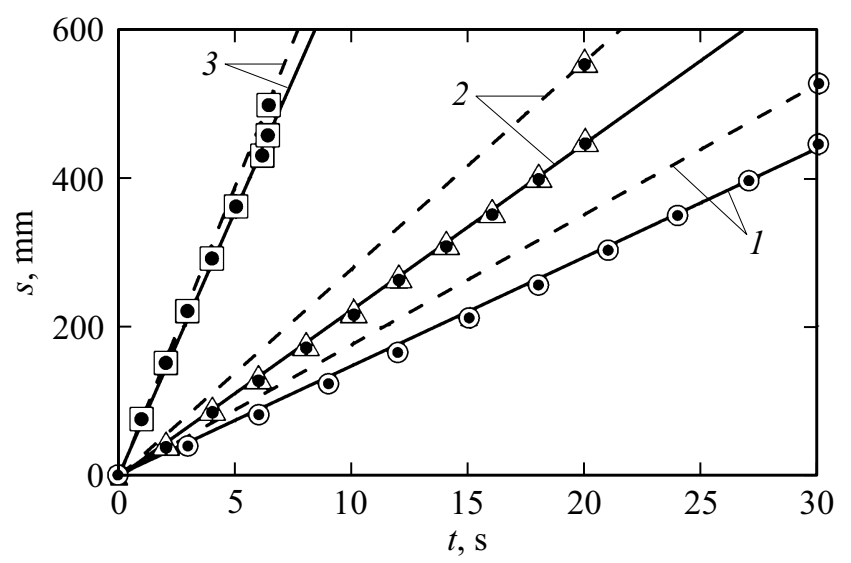

Рис. 1. Зависимость пройденного частицей расстояния в силиконовом масле ПМС-10000 от времени. $D_{p}=6.75(1)$, $8.73(2), 15.10 \mathrm{~mm}(3) . T_{p}=83 \mathrm{~K}$ (сплошные линии) и $293 \mathrm{~K}$ (штриховые).

Определение коэффициента гидродинамического сопротивления по измеренным значениям скорости осаждения частиц $u_{p}$ проводилось с использованием уравнения гравитационного осаждения частицы [13]:

$$
\rho_{p} V_{p} \frac{d u_{p}}{d t}=\left(\rho_{p}-\rho_{l}\right) V_{p} g-C_{D} S_{m} \frac{\rho_{l} u_{p}^{2}}{2},
$$

где $V_{p}$ - объем частицы.

При стационарном режиме движения $\left(d u_{p} / d t=0\right)$ из уравнения (3) следует формула для определения коэффициента сопротивления сферической частицы $\left(V_{p}=\pi D_{p}^{3} / 6, S_{m}=\pi D_{p}^{2} / 4\right)$

$$
C_{D}=\frac{4}{3} \frac{g D_{p}}{u_{p}^{2}}\left(\frac{\rho_{p}}{\rho_{l}}-1\right)
$$

Методом регрессионного анализа получены эмпирические зависимости для коэффициента гидродинамического сопротивления от безразмерной разности температур жидкости и частицы $\theta=\left(T_{l}-T_{p}\right) / T_{l}$ в диапазоне $\theta=0-0.717$

$$
u_{p}(\theta)=u_{p 0}\left(1-A \theta^{B}\right)
$$

где $u_{p 0}-$ скорость осаждения частицы в изотермических условиях.

Значения констант в (5) для глицерина $(\operatorname{Re}=0.5-1.32): A=0.336, B=0.620$; для ПМС-10000 $(\operatorname{Re}=0.01-0.1): A=0.202, B=0.962$. На рис. 2 приведены зависимости безразмерной скорости осаждения $\bar{u}_{p}(\theta)=u_{p}(\theta) / u_{p 0}$ от разности температур $\theta$, рассчитанные по формуле (5), а также экспериментальные данные по скорости осаждения, осредненные по пяти дублирующим экспериментам.

В области малых чисел Рейнольдса $\mathrm{Re} \sim 1$ коэффициент сопротивления определяется формулой Стокca $[14]$ :

$$
C_{D 0}=\frac{24}{\operatorname{Re}}=\frac{24 \mu_{l}}{\rho_{l} u_{p} D_{p}} .
$$




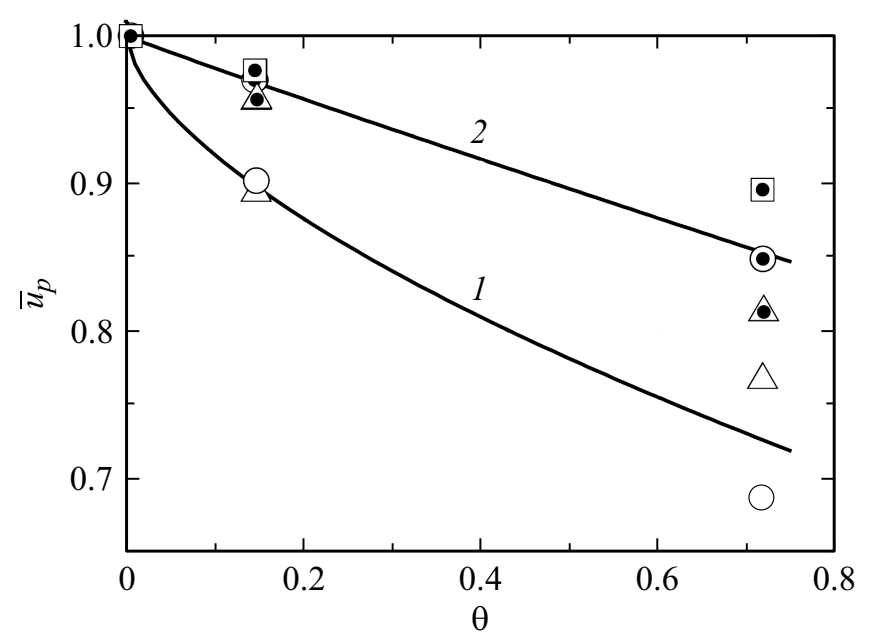

Рис. 2. Зависимость безразмерной скорости осаждения $\bar{u}_{p}$ от безразмерной разности температур $\theta .1-$ в глицерине, $2-$ в силиконовом масле ПМС-10000. $D_{p}=6.75$ (кружки), 8.73 (треугольники) и $15.10 \mathrm{~mm}$ (квадраты).

Подставляя в (6) аппроксимацию скорости осаждения (5), получим соотношение для расчета коэффициента гидродинамического сопротивления в неизотермических условиях для условий проведенных экспериментов:

$$
C_{D}(\theta)=\frac{C_{D 0}}{1-A \theta^{B}} .
$$

Обнаруженное в экспериментах увеличение коэффициента сопротивления для охлажденной твердой сферы можно объяснить изменением физических свойств жидкости вблизи частицы (в первую очередь увеличением вязкости) за счет перестройки температурного профиля. Проведенная обработка результатов экспериментов по эффективной температуре (пленочной температуре $\left.T_{f}=\left(T_{p}+T_{l}\right) / 2\right)$ показала, что выбор $T_{f}$ в качестве эффективной температуры приводит к существенным погрешностям при расчете скорости осаждения и соответственно коэффициента сопротивления твердой сферы в неизотермических условиях. Это связано, по-видимому, с нелинейностью зависимости вязкости жидкости от температуры.

Сравнение с результатами экспериментов с нагретыми твердыми сферами [15] показало, что при нагреве частиц в отличие от случая охлаждения шариков происходит увеличение скорости их осаждения и соответственно снижение коэффициента сопротивления с увеличением разности температур.

Получены новые экспериментальные данные по закономерностям гравитационного осаждения охлажденных до 83 и $250 \mathrm{~K}$ твердых сферических частиц в вязкой жидкости в области чисел Рейнольдса $\mathrm{Re}=0.01-1.32$, которые могут быть использованы для уточнения физико-математических моделей двухфазных течений применительно к различным технологическим процессам в условиях криогенных температур.

\section{Финансирование работы}

Работа выполнена при финансовой поддержке Минобрнауки РФ в рамках государственного задания № 0721-2020-0036.

\section{Конфликт интересов}

Авторы заявляют, что у них нет конфликта интересов.

\section{Список литературы}

[1] Р.И. Нигматулин, Динамика многобазных сред (Наука, М., 1987), ч. 1.

[2] И.П. Завершинский, Е.Я. Коган, Письма в ЖТФ, 26 (5), 76 (2000). https://journals.ioffe.ru/articles/viewPDF/37711

[3] D. Katoshevski, B. Zhao, G. Ziskind, E. Bar-Ziv, J. Aerosol. Sci., 32 (1), 73 (2001). DOI: $10.1016 / \mathrm{S} 0021-8502(00) 00057-4$

[4] G. Ziskind, B. Zhao, D. Katoshevski, E. Bar-Ziv, Int. J. Heat Mass Transfer, 44 (23), 4381 (2001). DOI: $10.1016 / \mathrm{S} 0017-9310(01) 00095-3$

[5] E. Mograbi, G. Ziskind, D. Katoshevski, E. Bar-Ziv, Int. J. Heat Mass Transfer, 45 (12), 2423 (2002). DOI: 10.1016/S0017-9310(01)00350-7

[6] E. Bar-Ziv, B. Zhao, E. Mograbi, D. Katoshevski, G. Ziskind, Phys. Fluids, 14 (6), 2015 (2002). DOI: 10.1063/1.1476305

[7] Н.В. Малай, Е.Р. Щукин, А.А. Стукалов, К.С. Рязанов, ЖТФ, 80 (3), 49 (2010). http://95.167.109.86/ bitstream/123456789/1449/1/Malai\%20N.V._K\%20vopros.pdf

[8] Н.В. Малай, А.В. Лиманская, Е.Р. Щукин, Дифференциальные уравнения, 51 (10), 1328 (2015).

DOI: 10.1134/S0374064115100076 [Пер. версия: 10.1134/ S0012266115100079].

[9] Н.В. Малай, А.В. Лиманская, Е.Р. Щукин, ПМТФ, 57 (2), 164 (2016). DOI: 10.15372/PMTF20160217 [Пер. версия: $10.1134 / \mathrm{S} 0021894416020176]$.

[10] S.A. Basalaev, V.A. Arkhipov, K.G. Perfilieva, A.S. Usanina, J. Phys.: Conf. Ser., 1214 (1), 012009 (2019). DOI: $10.1088 / 1742-6596 / 1214 / 1 / 012009$

[11] А.В. Лыков, Теория теплопроводности (Высш. шк., М., 1967).

[12] V.A. Arkhipov, S.S. Bondarchuk, V.V. Shekhovtsov, O.G. Volokitin, A.S. Anshakov, V.I. Kuzmin, Thermophys. Aeromech., 26 (1), 139 (2019). DOI: $10.1134 / \mathrm{S} 0869864319010141$

[13] В.А. Архипов, И.М. Васенин, А.С. Усанина, Г.Р. Шрагер, Динамическое взаимодействие частии дисперсной фазы в гетерогенных потоках (Изд. дом ТГУ, Томск, 2019).

[14] Г.И. Келбалиев, Теорет. основы хим. технологии, 45 (3), 264 (2011). https://elibrary.ru/download/elibrary_16352677_ 65608346.pdf

[15] В.А. Архипов, А.А. Антонникова, С.А. Басалаев, К.Г. Перфильева, Оптика атмосферы и океана, 32 (6), 495 (2019). https://www.elibrary.ru/item.asp?id=38512474 